\title{
The downregulation of $\Delta$ Np63 in p53-deficient mouse epidermal tumors favors metastatic behavior
}

\author{
Olga Bornachea ${ }^{1}$, Fernando F. López-Calderón ${ }^{1,2}$, Marta Dueñas ${ }^{1,2}$, Carmen \\ Segrelles $^{1,2}$, Corina Lorz ${ }^{1,2}$, Cristian Suárez-Cabrera ${ }^{1,2}$, María Marañón ${ }^{1}$, Beatriz \\ ${\text { Paradela-Dobarro', }{ }^{1} \text { Mirentxu Santos }}^{1,2}$, Jesús M. Paramio, \\ ${ }^{1}$ Molecular Oncology Unit, CIEMAT, 28040 Madrid, Spain \\ ${ }^{2}$ Molecular Oncology, Institute of Biomedical Investigation University Hospital, 28041 Madrid, Spain
}

Correspondence to:

Mirentxu Santos, e-mail: mirentxu.santos@ciemat.es

Jesús M. Paramio, e-mail: jesusm.paramio@ciemat.es

Keywords: p63, p53, metastasis, miRNA, skin

Received: May 05, 2015

Accepted: June 19, 2015

Published: July 01, 2015

\section{ABSTRACT}

The TP63 gene codes for two major isoform types, TAp63 and $\Delta$ Np63, with probable opposite roles in tumorigenesis. The $\Delta \mathrm{Np63a}$ protein is frequently amplified and overexpressed in different epithelial tumors. Accordingly, it has been considered a potential oncogene. Nonetheless, a possible metastatic suppressor activity has also been suggested based on the experimental observation that its expression is reduced or even absent in advanced invasive tumors. Such metastatic suppressor activities are often related to tumors bearing point mutated TP53 gene. However, its potential roles in TP53-deficient tumors are poorly characterized. Here we show that in spontaneous tumors, induced by the epidermal-specific Trp53 ablation, the reduction of $\Delta N p 63$ expression is an early event, whereas it is re-expressed in the lung metastatic lesions. Using knock down and ectopic expression approaches, we show that $\Delta N p 63$ expression opposes the epithelial-mesenchymal transition and reduces the metastatic potential of the cells. This process occurs through the modulation of $\Delta \mathrm{Np} 63$-dependent downstream targets (including transcription factors and microRNAs) likely to play metastatic roles. Further, $\Delta \mathrm{Np} 63$ also favors the expression of factors involved in iPS reprogramming, thus suggesting that it can also modulate specific stem cell traits in mouse epidermal tumor cells. Overall, our data assign antimetastatic roles to $\Delta \mathrm{Np} 63$ in the context of p53 deficiency and epidermis.

\section{INTRODUCTION}

The TP63 gene forms, together with TP53 and $T P 73$, the so-called p53 family. These genes produce multiple isoforms due to alternative splicing and alternative promoter usage [1]. The resulting proteins exert specific roles in development, differentiation and cancer progression [2]. This last aspect is highlighted by the extremely frequent mutations affecting the TP53 gene in multiple human tumors, which in general are associated with increased malignancy and poor clinical outcome [3-5]. However, the roles of the other p53 family members in the context of cancer are less understood. This could be attributed to the differential expression of multiple isoforms with distinct properties. In the case of $T P 63$, by the use of alternative promoters, two major isoform types are transcribed, named TAp63 and $\Delta \mathrm{Np} 63$, with different and often opposing functional properties [6]. TAp63 can induce cell cycle arrest and apoptosis and participates in the DNA damage response $[7,8]$, functions commonly attributed to the $\mathrm{p} 53$ family. $\Delta \mathrm{Np} 63$ is primarily expressed in the basal layer of most stratified epithelia and exerts essential functions in epithelial development and differentiation $[9,10]$. In the context of cancer, the roles of these isoforms and their possible crosstalk with p53 are still partially obscure. With few exceptions, mutations of the TP63 gene are rare in human malignancies, suggesting that it is not a canonical tumor suppressor. On the contrary, several human tumors display overexpression and also amplification of this gene, suggesting a potential 
oncogenic role [11]. This last aspect is particularly relevant for the $\Delta \mathrm{Np} 63 \alpha$ isoform, which is specifically amplified and overexpressed in multiple stratified epithelia-derived tumors [12], promotes the activation of stratified-epithelia relevant oncogenic pathways [13], can mediate resistance to chemotherapy [14], and overcome the oncogene-induced senescence [15]. Nonetheless, in some aggressive metastatic epithelial tumors the expression of $\triangle \mathrm{Np} 63$ is reduced and often lost, suggesting potential roles as metastasis suppressor [16-21]. This is in agreement with the observed ability of $\Delta \mathrm{Np} 63$ to bind and modulate the expression of a variety of genes, including transcription factors, adhesion and signaling molecules, and also several miRNAs [14, 20, 22-25]. In addition, these roles may also explain why the limited metastatic spreading of spontaneous tumors arising in Trp53-/mice is significantly enhanced by simultaneous ablation of the Trp63 gene [26]. However, the potential opposite differences affecting the functional roles of TAp63 and $\Delta \mathrm{Np} 63$ isoform types makes the possible contribution of these proteins a complex issue. Therefore, further research is clearly needed to ascertain the actual oncogenic and/or metastatic suppressor roles of $\Delta \mathrm{Np} 63$ in order to consider possible targeted therapies.

The functional interaction between p53- and p63-dependent signaling pathways has remained poorly investigated until recently, when two new mechanisms have been described. These implicated the physical interaction between p63 and mutant p53 in the context of TGF $\beta$ signaling, leading to the inhibition of various genes involved in metastasis and whose expression is regulated by p63 [27, 28]. Although the possible differences affecting TAp63 and $\Delta$ Np63 isoform types in this context have not been completely elucidated, these findings reinforce a possible role of p63 as a metastasis suppressor and also may help to explain the gain of function of missense mutations of the TP53 gene and their involvement in the increased malignancy observed in human p53-mutant tumors [29-31]. Nevertheless, human tumors also frequently display absence of $\mathrm{p} 53$ expression due to deletion of the TP53 gene, and the occurrence of TP53 gene point mutations leading to premature stop codon generation. The potential roles of $\mathrm{p} 63$ in this context of p53 loss are almost completely unknown.

We have previously reported that the specific ablation of Trp53 in mouse stratified epithelia (hereafter $\operatorname{Trp} 53^{4 E p i}$ mice) leads to spontaneous tumor development [32]. These tumors arise primarily in the epidermis and their onset is accelerated by the concomitant loss of other tumor suppressors such as $R b 1$ and Pten [32, 33]. Importantly, the transcriptome analyses of these mouse tumors revealed massive overlapping with multiple human tumors characterized by poor prognosis, metastatic spreading and p53 mutation [34]. This overlap is not limited to human skin cancers, and includes multiple tumors of high clinical relevance arising in tissues such as breast and lung [35]. Interestingly, the transcriptome analysis also revealed a significant enrichment of stem cell-like signatures in these p53deficent tumors [34], which are also associated with the metastatic spreading of human tumors [36]. More recently we also demonstrated the high metastatic capacity of these $\operatorname{Trp} 53^{4 E p i}$ tumors, and we characterized a role for specific miRNAs in this process through a possible modulation of the epithelial mesenchymal transition (EMT) signaling pathway [37]. EMT is a critical process during embryonic development and has also been recognized as a potential mechanism for carcinoma metastasis [38, 39]. During EMT, epithelial cells lose cell-to-cell adhesion and cell polarity to gain mesenchymal features, providing motility and invasiveness. This is accomplished by an intricate network of transcription factor activation, including TWIST, SNAIL, SLUG, ZEB1 and ZEB2 which are also under epigenetic regulation through various miRNAs [38, 40, 41]. Importantly, recent evidences also support a role for $\Delta$ Np63 modulating EMT $[18,19]$. Here we report that spontaneous tumors arising in Trp $53^{4 E p i}$ mice display early repression of $\Delta \mathrm{Np} 63$ expression. Using overexpression and knock down approaches, we also observe that altered expression of $\Delta \mathrm{Np} 63$ leads to the disturbed expression of various transcription factors and miRNAs involved in the acquisition of stem cell-like characteristics and in the EMT process.

\section{RESULTS}

\section{Reduced $\Delta$ Np63 expression is an early event in $\operatorname{Trp53}^{4 E p i}$ spontaneous tumors}

Immunohistochemical analyses revealed that the pattern of p63 expression in the skin of $\operatorname{Trp} 53^{4 E p i}$ and $\operatorname{Tr} p 53^{\triangle E F i} ; R b 1^{1 E p i}$ mice is undistinguishable from control $\mathrm{wt}$ mice (Fig. 1A, 1E), and remains expressed, mainly in the basal layer, in areas of epidermal dysplasia (Fig. 1B, 1E). However, its expression is drastically reduced in squamous cell carcinoma (SCC) (Fig. 1C, 1E) and almost completely absent in spindle cell carcinomas (SpCC) (Fig. 1D, 1E). Since the antibody used reacts with all p63 isoforms, we also performed a qRT-PCR analysis using primers specific for the $\Delta \mathrm{Np} 63$ isoform. This revealed the systematic reduction of this isoform in mouse tumors (Fig. 1F). These findings were corroborated by western blot analyses (Fig. 1G), which also showed that $\Delta \mathrm{Np} 63 \alpha$, the major isoform expressed in skin, is absent in most tumors, although some of them expressed p63 isoforms of lower molecular weight (indicated by arrow in Fig. 1G). We also studied the p63 expression in the spontaneous metastatic lesions arising in the lungs of $\operatorname{Tr} p 53^{\triangle E p i}$ or $\operatorname{Tr} p 53^{4 E D i} ; R b 1^{\triangle E p i}$ mice. We found that these lesions display positive p63 staining (Fig. 1H, H'), suggesting that the observed 

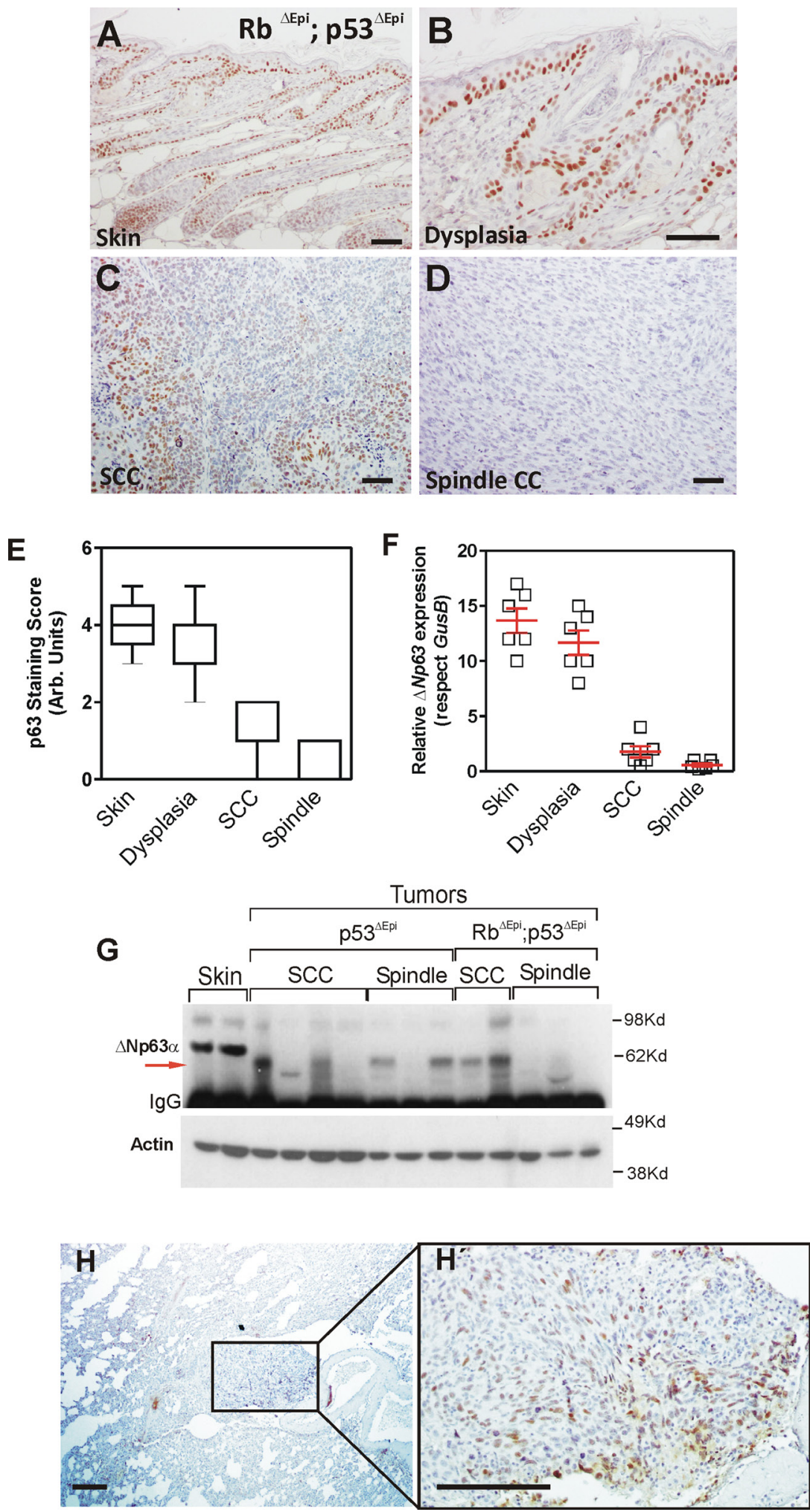

Figure 1: $\Delta$ Np63 downregulation is an early event in spontaneous Trp53-deficient epidermal tumors. A-D. Representative examples of p63 expression in non lesional epidermis (A), dysplasia (B), moderately differentiated tumor (C) and undifferentiated tumor from $R b 1^{4 E p i}$;rp $53^{4 E p i}$ mice as assessed by immunohistochemistry. E-F. Summary of p63 expression in samples determined by immunohistochemistry (E) or qRT-PCR (F) G. Immunoblot of the quoted protein extracts showing the expression of p63 isoforms. Note the lack of $\Delta \mathrm{Np} 63 \alpha$ expression in tumors, regardless their genotype, and the presence of a fast migrating isoform in some of them (denoted by red arrow). H, H'. Representative examples of p63 expression in lung metastases. H' is a high magnification of the area denoted in $\mathrm{H}$ covering the metastatic nodule. Bars $=150 \mu \mathrm{m}$ 
reduction of $\Delta \mathrm{Np} 63 \alpha$ expression in the primary tumors is not attributable to gene loss or deletion, but rather to a transcriptional repression.

\section{The expression of $\Delta \mathrm{Np} 63$ opposes EMT in $\operatorname{Trp53^{4Epi}}$ tumors}

To study the functional consequences of the reduced p63 expression, we sought to express hu $\Delta \mathrm{Np} 63 \alpha$ in the $940 \mathrm{SpCC}$ cells [37]. These cells were derived from a $\operatorname{Trp} 53^{\triangle E p i} ; R b 1^{\triangle E p i}$ mouse spontaneous primary tumor, which also showed lung metastasis [37]. Compared with COCA immortalized keratinocytes [42], the 940 cells are characterized by a spindle morphology (Supplementary Fig. 1A, 1B), absence of p53 and TAp73 $\alpha$ expression, severe reduction of
$\Delta \mathrm{Np} 63 \alpha$ expression, and increased expression of $\Delta \mathrm{Np} 73 \alpha$ (Supplementary Fig. 1C). In these cells, the pharmacological treatment to inhibit specific pathways that can mediate p63 repression leads to partial increase in $\triangle N p 63$ (Supplementary Fig. 1D). However, its levels never reached those observed in immortalized COCA keratinocytes (Supplementary Fig. 1D). Previous data also showed that 940 cells are highly metastatic when injected either subcutaneously or in the tail vein of immunocompromised mice [37], whereas COCA cells are not tumorigenic [42]. We used a lentiviral vector, which also expressed the EGFP protein, to ectopically express hu $\Delta \mathrm{Np} 63 \alpha$, and transduced cells were sorted based on EGFP fluorescence. Compared to the control EGFP transduced cells (Fig. 2A, 2E), the majority of the 940 cells transduced with hu $\Delta \mathrm{Np} 63 \alpha$ showed the expression of
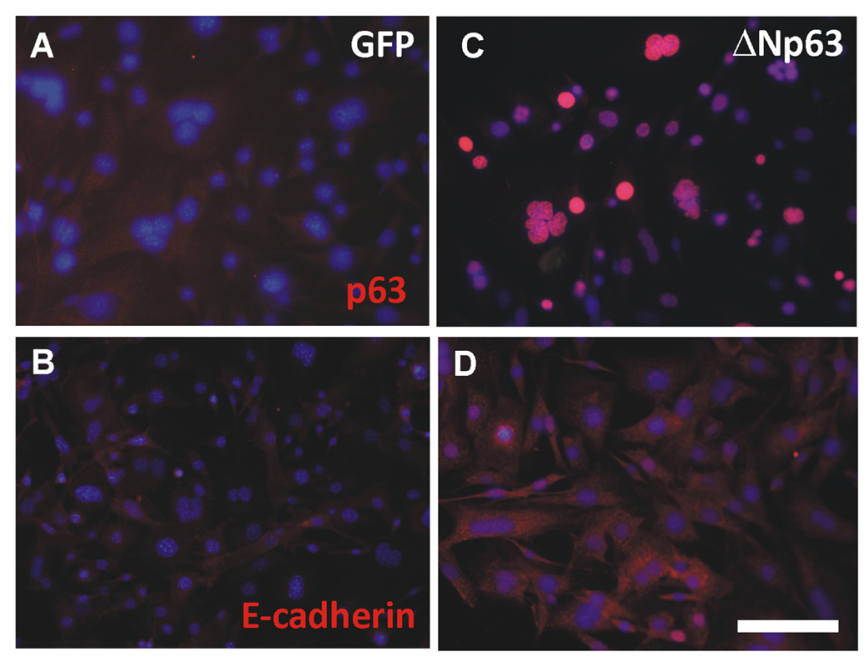

H

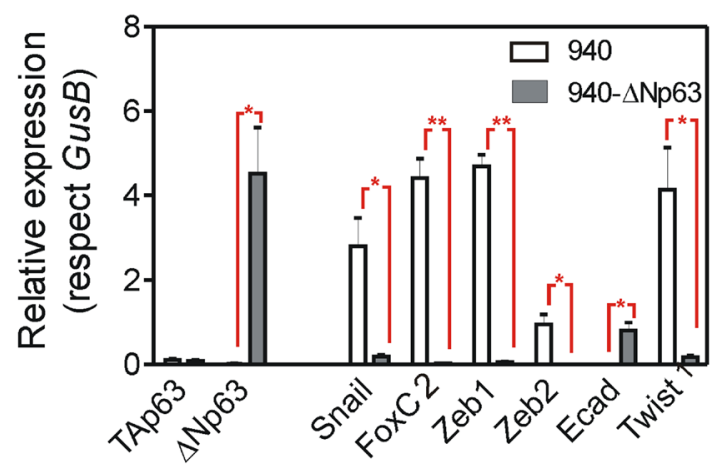

I
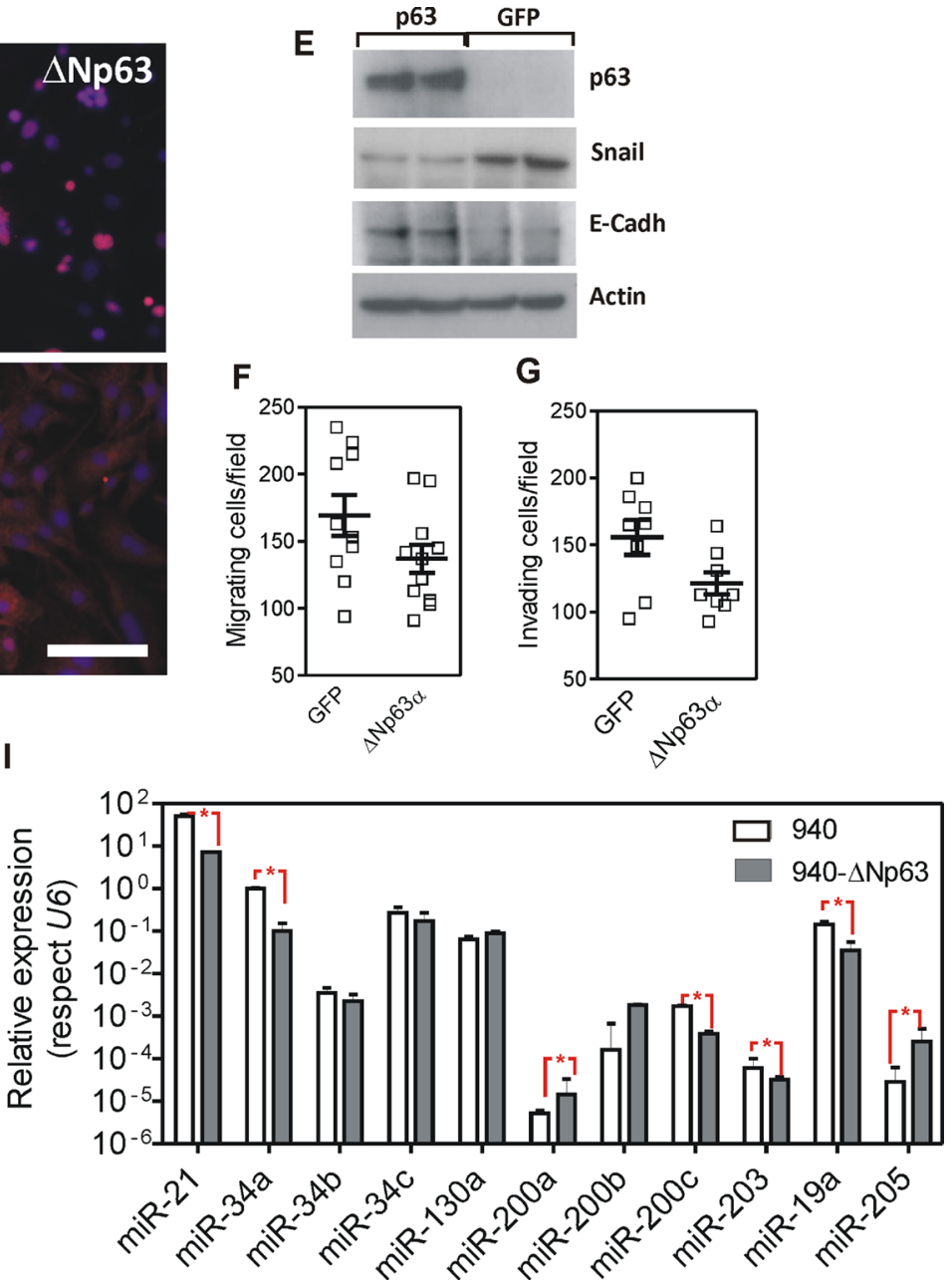

Figure 2: Expression of hu $\Delta \mathrm{Np63 \alpha}$ in 940 cells ameliorates EMT process. A-D. Representative immunofluorescence images of 940 cells traduced with GFP (A, B) or $\Delta \operatorname{Np} 63 \alpha(C, D)$ showing the expression and localization of p63 (A, C) and E-Cadherin (B, D). E. Immunoblot of the quoted protein extracts showing the expression of p63, Snail and E-cadherin. Actin was used to normalize loading. F, G. Determination of migratory (F) and invasive (G) properties of 940 cells upon transduction with GFP or $\Delta$ Np63 $\alpha$ coding lentiviruses. H, I. Determination of the expression of transcription factors $(\mathrm{H})$ and miRNAs (I) involved in EMT processes as assessed by qRT-PCR analyses. Data came from at least quadruplicated experiments. *denotes $p$ value $<0.05$, **denotes $p$ value $<0.01$ Bars $=150 \mu \mathrm{m}$ 
the transduced gene (Fig. 2C, 2E). Importantly, although no major changes in cell morphology were detected upon hu $\Delta \mathrm{Np} 63 \alpha$ expression (not shown), we observed a partial increase in E-cadherin expression, which was not properly localized at the cell-cell contacts (Fig. 2B, 2D, $2 \mathrm{E})$. Moreover, the expression of hu $\Delta \mathrm{Np} 63 \alpha$ produces a limited inhibition of the migratory (Fig. 2F) and invasive (Fig. 2G) characteristics of the 940 cells. The silencing of the $C d h 1$ gene (coding for E-cadherin) is an early marker and a prerequisite for the EMT process. This event is promoted by the concerted action of various transcription factors including Snail, FoxC2, Zeb1, Zeb2 and Twist1, which are also induced early in the spontaneous tumors arising in Trp53 $3^{4 E p i}$ mice [37]. We observed that the expression of hu $\Delta \mathrm{Np} 63 \alpha$ in 940 cells induced a significant decrease in the expression of all these transcription factors that promote EMT (Fig. 2E, 2H). Remarkably, none of these genes have been identified as bound by p63 [20, 22-25], suggesting that such reduction is not directly mediated by p63 binding to their respective promoters.

Several miRNA modulate the EMT process [40, $43,44]$ and are regulated by p53 and/or p63 [14, 24, 45]. These include miR21, miR200 family, miR34 family, miR130a, miR203, miR19a and miR205. We thus analyzed whether the expression of these miRNAs was affected by the ectopic expression of $\mathrm{Hu} \Delta \mathrm{Np} 63 \alpha$ in 940 cells. We observed a significant reduction in the expression of miR21, miR34a, miR200c, miR203 and miR19a, whereas miR200a, miR200b and miR205 displayed increased expression in $\mathrm{Hu} \Delta \mathrm{Np} 63 \alpha$-expressing 940 cells (Fig. 2I). Importantly, the reduction of miR21, miR19a and miR203, and the increased expression of miR200a, miR200b and miR205 are compatible with a possible reduction in the metastatic potential of 940 cells upon ectopic expression of hu $\Delta \mathrm{Np} 63 \alpha$, and may explain the indirect regulation of EMT-mediating transcription factors described above.

Collectively, these data indicate that $\mathrm{p} 63$ expression opposes EMT, probably through the indirect modulation of the expression of various transcription factors due to altered miRNA expression, but it is unable to completely reverse this process, as shown by the absence of significant changes in cell morphology and E cadherin localization.

\section{$\Delta$ Np63 expression delays metastatic spreading}

To ascertain whether the functional consequences of the deregulated expression of miRNAs and reduced expression of transcription factors induced by hu $\Delta \mathrm{Np} 63 \alpha$ cells may result in altered metastatic spreading of these cells, we subcutaneously injected control or hu $\Delta \mathrm{Np} 63 \alpha-$ transduced cells in the flank of athymic (nu/nu) mice. We observed that mice developed tumors with similar incidence regardless the cells injected (Fig. 3A). Further, the spindle histology of the tumors was similar between control and hu $\Delta \mathrm{Np} 63 \alpha$-transduced cells (not shown).
However, the tumors generated by hu $\Delta \mathrm{Np} 63 \alpha$-transduced cells displayed a partial delayed growth compared with the controls (Fig. 3B). In spite of this observation, the cell cycle profiles were similar in control and in hu $\Delta \mathrm{Np} 63 \alpha-$ transduced cells (Supplementary Fig. 2A).

To monitor possible metastatic outgrowths, the cohort of mice was split into two subgroups. In one of them the lungs were analyzed immediately after sacrifice, whereas in the other the subcutaneous tumors were surgically removed, and mice were euthanized one month later. In the first group the hu $\Delta \mathrm{Np} 63 \alpha$-transduced displayed reduced lung metastasis incidence (percentage of lung lobules bearing metastatic lesions) compared to control cells (Fig. 3C, C', 3D), and also a reduced number of metastatic nodules (number of metastatic lesions per lung lobule) (Fig. 3C, C', 3E), indicating that the forced expression of hu $\Delta \mathrm{Np} 63 \alpha$ caused a delayed metastatic spreading. However, these differences were not observed when the tumors were surgically removed and mice kept alive for further 30 days (Fig. 3F, 3G). Nonetheless, we observed that the number of cells expressing hu $\Delta \mathrm{Np} 63 \alpha$ in the subcutaneous tumors was very low (Fig. 4A, A') compared with the parental cells injected (Fig. 2C). As expected, no p63 expression was observed in tumors produced by the injection of control EGFP-expressing cells (Fig. 4B, B'). To further support this finding, we performed qRT-PCR of hu $\Delta \mathrm{Np} 63 \alpha$ from transduced cells, subcutaneous tumors and lungs bearing metastatic nodules. We observed a significant reduction in tumors compared with cells, which is further reduced in the lungs (Fig. 4C).

The metastatic dissemination depends on various sequential events: invasion intravasation, survival in the blood stream, extravasation and colonization of the target organ. To study whether the last steps of the process were affected by hu $\Delta \mathrm{Np} 63 \alpha$ expression, control and hu $\Delta \mathrm{Np} 63 \alpha$-transduced cells were injected in the tail vein of athymic $(n u / n u)$ mice. Upon sacrifice we detected a reduced number of lung nodules in the case of hu $\Delta \mathrm{Np} 63 \alpha-$ transduced cells compared to control cells (Fig. 5A, A', 5C) in spite of similar metastatic incidence (Fig. 5B). The reduced lung colonization was further confirmed by measuring the lung area covered by nodules, which was also reduced in the case of hu $\Delta \mathrm{Np} 63 \alpha$-transduced cells (Fig. 5D). Nonetheless, we also observed that the number of cells expressing hu $\Delta \mathrm{Np} 63 \alpha$ was severely low in the metastatic nodules (Fig. 5E), in agreement with the PCR observations (Fig. 4C). Collectively these findings indicated that hu $\Delta \mathrm{Np} 63 \alpha$ caused a partial inhibition of metastatic spreading. However, our data also suggested that hu $\Delta \mathrm{Np} 63 \alpha$ expression caused a potential growth disadvantage in vivo, and was probably silenced during tumor growth and metastatic spreading. This led to a reduced presence of cells expressing hu $\Delta \mathrm{Np} 63 \alpha$ in the tumors and metastases. 
A
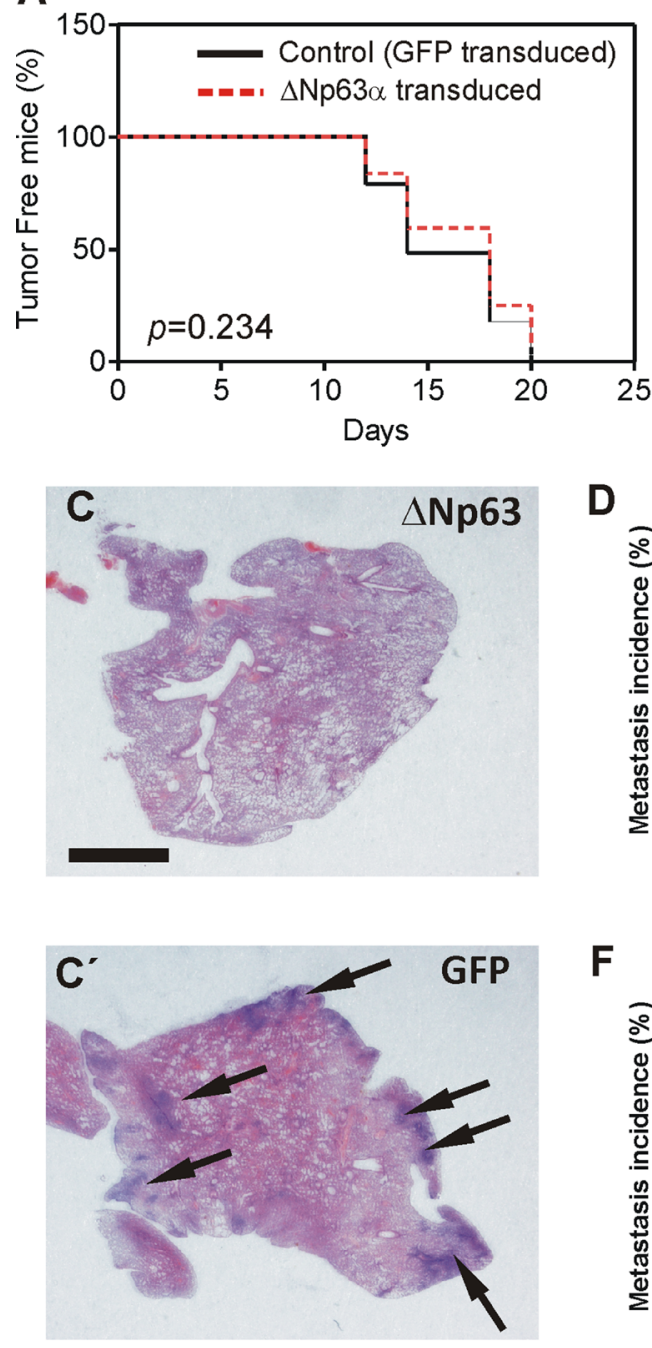

D

$\mathbf{F}$
B
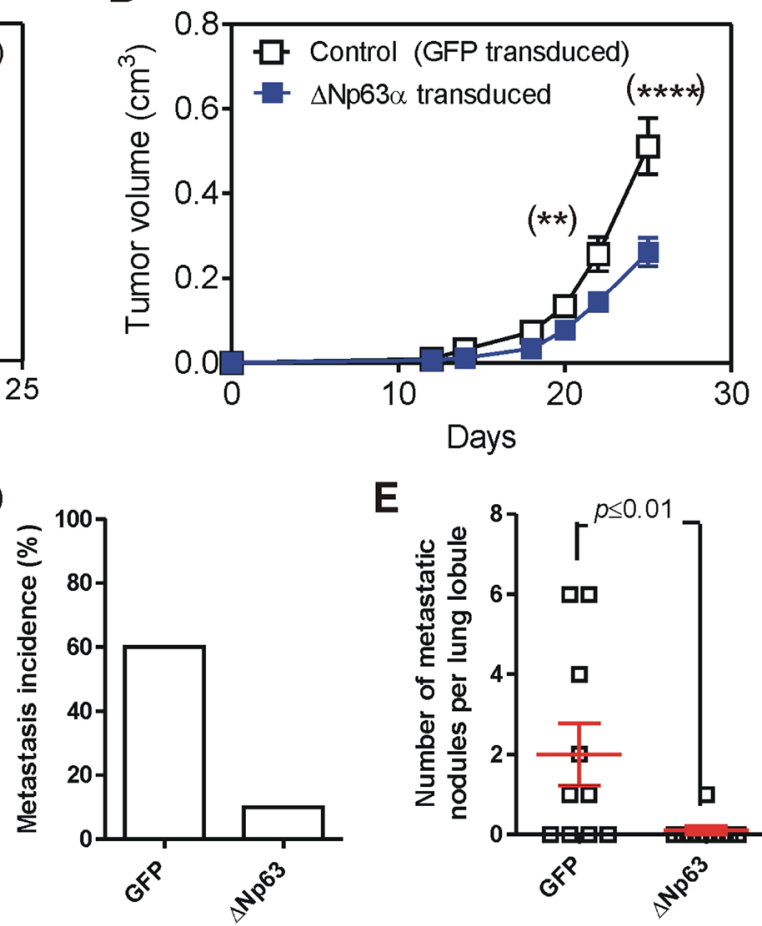

E
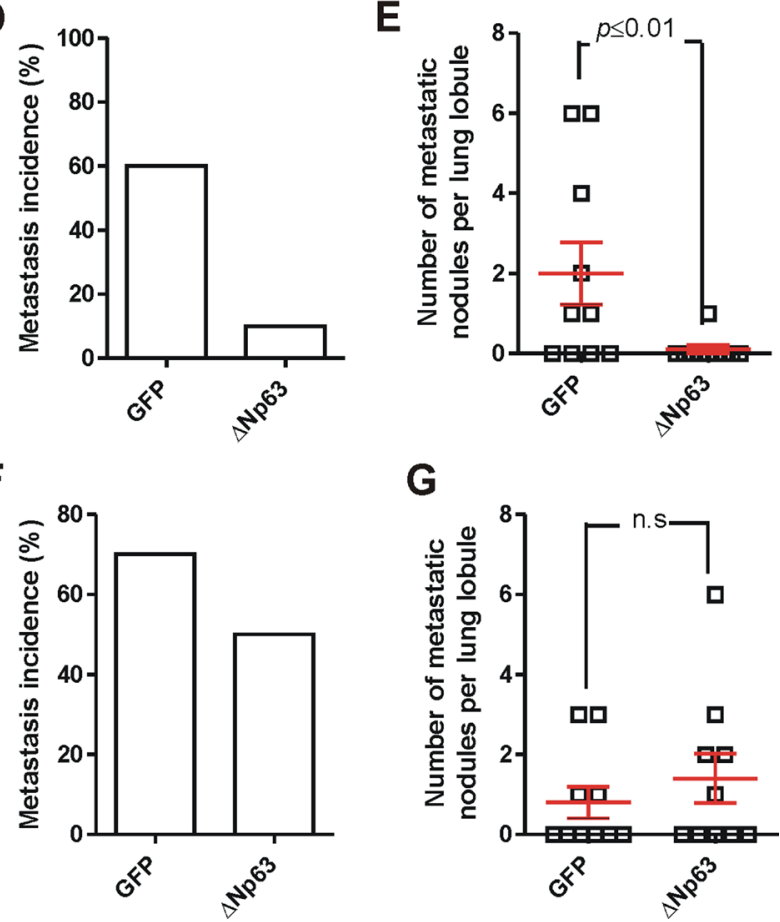

G

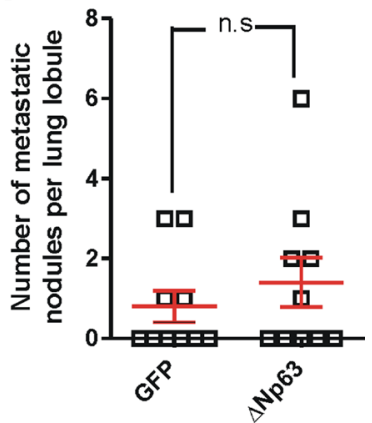

Figure 3: Expression of hu $\Delta \mathrm{Np63 \alpha}$ decreases spontaneous metastasis development. A. Tumor incidence upon subcutaneous injection of 940 cells upon transduction with GFP (black line) or $\Delta \mathrm{Np} 63 \alpha$ (red line) coding lentiviruses determined by Kaplan Meyer curves. $P$ Value was determined by $\log$ rank test. B. Tumor growth of subcutaneously injected 940 (open squares) or hu $\Delta \mathrm{Np} 63 \alpha$ (blue squares) cells. $P$ Value was determined by 2 Way ANOVA followed by Bonferroni post-test. *denotes $p$ value $<0.05, * * * *$ denotes $p$ value $<0.0001$. C, C'. Representative images of H\&E stained lung lobule sections showing the presence of metastatic nodules (denoted by arrows) upon tumor induction by subcutaneous injection of 940 cells upon transduction with $\Delta \mathrm{Np} 63 \alpha(\mathrm{C})$ or GFP (C') coding lentiviruses. Bar $=0.5 \mathrm{~cm}$ D, E. Summary of lung metastasis incidence (D) and number of metastatic nodules per lung lobule (E) observed in mice bearing subcutaneously injected with 940 or hu $\Delta \mathrm{Np} 63 \alpha$ cells and sacrificed one month after injection. F, G. Summary of lung metastasis incidence (D) and number of metastatic nodules per lung lobule (E) observed in mice one month after surgical removing the subcutaneous tumors produced by 940 or hu $\Delta \mathrm{Np} 63 \alpha 940$ cells.

\section{Reduced $\Delta \mathrm{Np63}$ expression favors EMT}

The above described results indicated that the forced expression of hu $\Delta \mathrm{Np} 63 \alpha$ in p53-deficient cells reduces metastatic behavior and the expression of genes and miRNAs that mediate EMT. To monitor whether the reduced expression of $\mathrm{p} 63$ facilitates these events, we used knock down approaches in PB keratinocytes. These cells were isolated from a chemically induced mouse papilloma and bear Trp53 mutations [46]. Upon subcutaneous injection they render mostly differentiated SCCs and no metastasis [47]. We used two different shRNA lentiviral constructs that significantly reduced the endogenous p63 expression as confirmed by immunoblot (Fig. 6A) and qPCR (Fig. 6B) affecting both $\triangle \mathrm{N}$ and TA isoforms. Importantly, although TAp63 can be detected by qPCR (Fig. 6B), its levels are extremely low (not shown), thus suggesting that the possible changes observed 

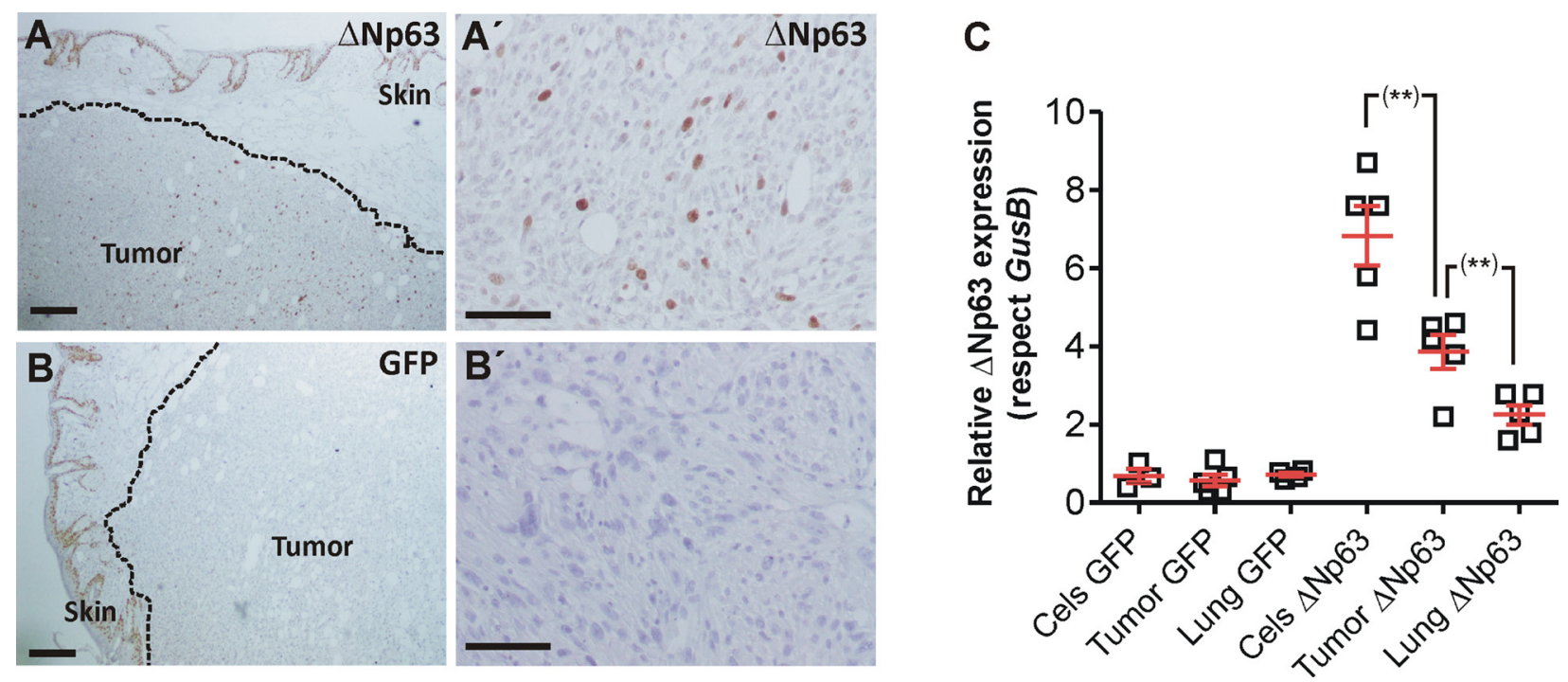

Figure 4: hu $\Delta \mathrm{Np} 63 \alpha$ expression is downregulated during spontaneous metastasis development. A, A'. Representative immunohistochemistry image showing p63 expression in subcutaneous tumors produced by the injection of hu $\Delta \mathrm{Np} 63 \alpha 940$ cells B, B'. Representative immunohistochemistry images showing p63 expression in subcutaneous tumors produced by the injection of 940 cells C. Summary of qRT-PCR determination of hu $\Delta \mathrm{Np} 63 \alpha$ expression upon transduction with GFP or $\Delta \mathrm{Np} 63 \alpha$ coding lentiviruses cells, and in the tumors and lung metastases after subcutaneous injection of the cells. Bars $=150 \mu \mathrm{m}$

(see below) are not primarily attributable to the decreased TAp63 levels. Immunofluorescence analysis corroborated the reduction of $\Delta \mathrm{Np} 63$ expression (Fig. $6 \mathrm{C}, \mathrm{C}^{\prime}$ ) and suggested a concomitant decrease in E-Cadherin in the p63 silenced cells (Fig. 6D, D'). Immunoblot and qPCR studies showed that the decreased $\Delta \mathrm{Np} 63$ expression in $\mathrm{PB}$ cells was accompanied with a significant increase in Snail, Twist1, Zeb1 and FoxC2 expression, and confirmed the reduction of E-cadherin (Fig. 6E, 6F). In agreement, the reduced expression of p63 also accounted for increased invasiveness, but not migratory properties, of the $\mathrm{PB}$ keratinocytes (Fig. 6G, G'). Finally, the reduction of p63 levels also affected the expression of several miRNAs (Fig. 6H), in agreement with the data obtained with hu $\Delta$ Np63 $\alpha$-expressing 940 cells (Fig. 2I). These data indicated that reduced p63 expression favored EMT in PB keratinocytes.

We next assayed the in vivo tumorigenic properties of control and shp63 PB cells upon subcutaneous injection in $n u / n u$ mice. No differences in tumor appearance were observed (Fig. 7A), although tumor growth was slightly faster in p63-silenced cells (Fig. 7B), despite no significant differences in cell cycle profiles were detected between PB and PBshp63 cells (Supplementary Fig. 2B). The subcutaneous tumors displayed undifferentiated and differentiated areas (denoted by arrows in Fig. 7C). Importantly, tumors produced by PBshp63 cells displayed increased undifferentiated phenotype (Fig. 7D), and increased muscle invasiveness (Fig. 7E, 7F, 7G). Immunohistochemistry analyses revealed that, in parental PB cell-induced tumors, many muscle-invading cells displayed reduced p63 expression (Fig. $7 \mathrm{H}$ ), similarly to tumors produced by PBshp63 cells (Fig. 7H').
In spite of the increased invasiveness, only one mice subcutaneously injected with PBshp63 cells displayed a small lung nodule (Fig. 7I), whereas none of the controls showed lung metastatic lesions (not shown). We thus monitored the metastatic capacity of control and PBshp63 cells upon intravenous injection. Similarly to the subcutaneously injected mice, no overt metastases were observed one month after the tail vein injection of either control or shp63 cells. Nonetheless, 4 out of 5 mice injected with the p63-silenced cells displayed the presence of epithelial cell aggregates in the lung blood vessels (Fig. 7J). This may indicate that, although the downregulation of p63 favors EMT process, it is insufficient to promote the overt metastatic behavior of the PB keratinocytes due, in part, to an impairment of the extravasation and colonization in the lungs.

\section{$\Delta \mathrm{Np63}$ expression regulates pluripotency genes}

The EMT process is associated with the acquisition of stem cell-like properties [38], and tumors with increased aggressiveness also display ES-like genomic features [36]. Accordingly, cancer cells present some remarkable similarities with embryonic stem cells, including unlimited proliferation and self-renewal, and the expression of pluripotency genes, such as NANOG, OCT4 or SOX2 [48]. Of relevance, SOX2, OCT4 and NANOG are also particularly involved in squamous cell carcinoma malignization and progression [49-51]. More recently, it has been reported that p63 can also alter the iPS generation from adult epithelial cells [52]. Consequently, the altered metastatic behavior produced by $\Delta \mathrm{Np} 63$ could also be related to the expression of pluripotency genes. 

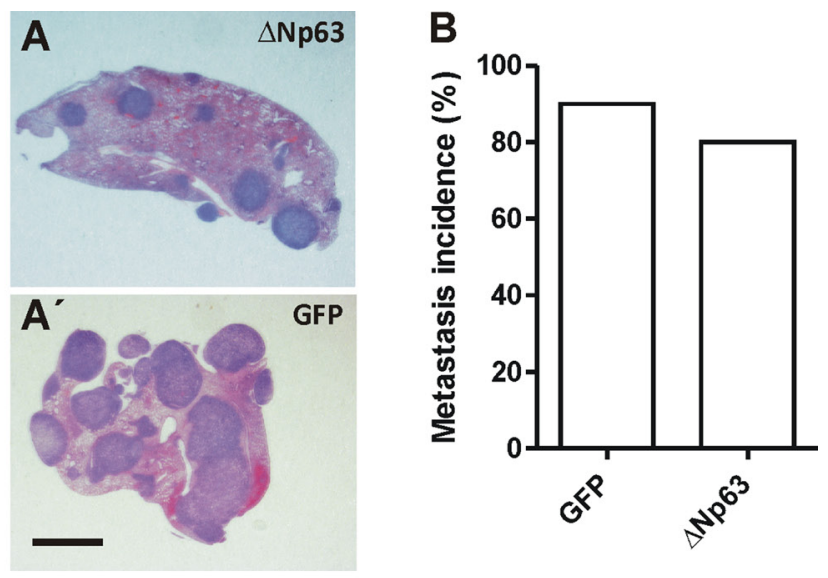

D
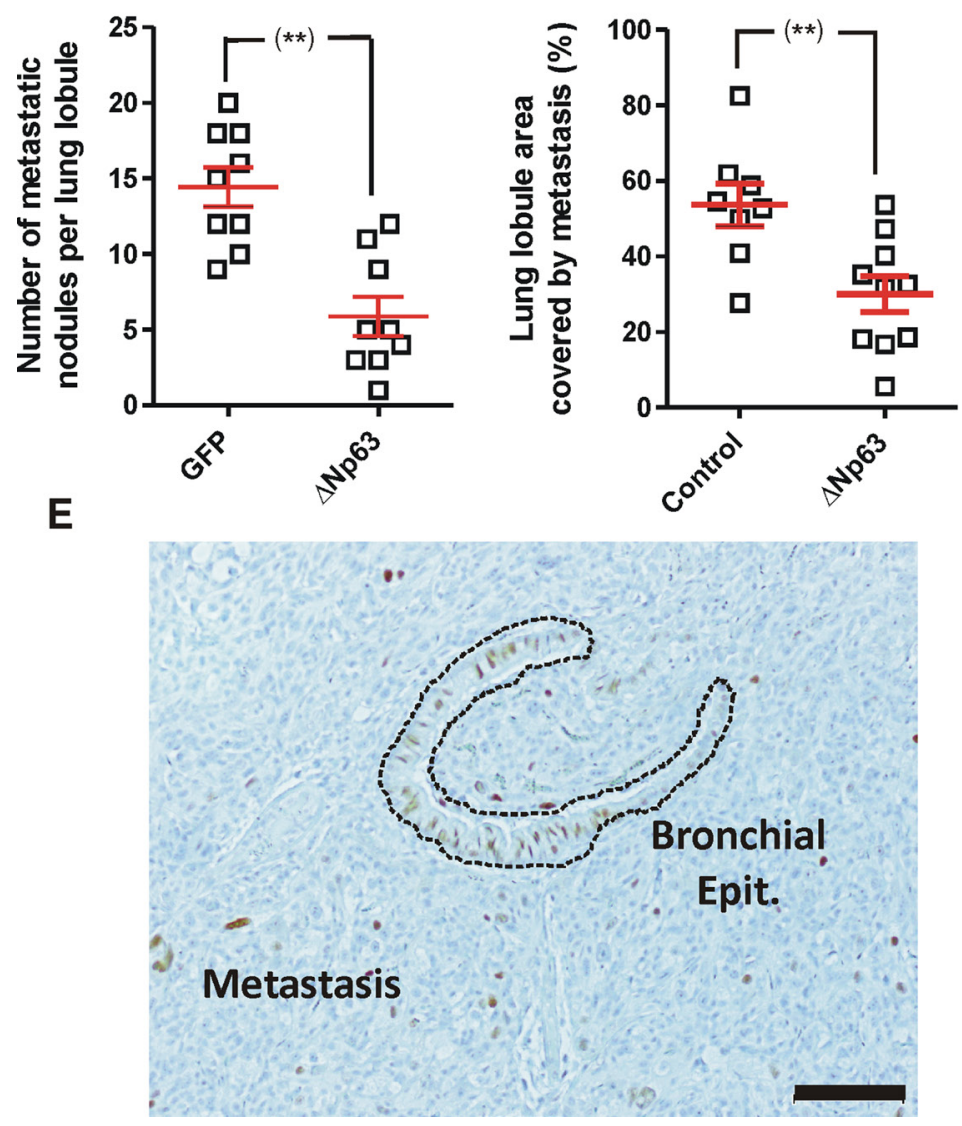

Figure 5: Expression of hu $\Delta \mathrm{Np63 \alpha}$ decreases experimental metastasis development. A, A'. Representative images of H\&E stained lung lobule sections showing the presence of metastatic nodules upon tail vein injection of 940 cells upon transduction with $\Delta \mathrm{Np} 63 \alpha$ (A) or GFP (A') coding lentiviruses. Bar $=0.5 \mathrm{~cm}$ B-D. Summary of lung metastasis incidence (B), number of metastatic nodules per lung lobule (C) and lung area covered by metastatic nodules (D), observed in mice injected into the tail vein with 940 or hu $\Delta \mathrm{Np} 63 \alpha$ cells and sacrificed one month after injection. **denotes a $p$ value $<0.01$ E. Representative immunohistochemistry image showing p63 expression in a lung metastasis produced by the tail vein injection of hu $\Delta \mathrm{Np} 63 \alpha 940$ cells. Bar $=250 \mu \mathrm{m}$.

We thus analyzed whether these genes were affected by the forced expression of hu $\triangle \mathrm{Np} 63 \alpha$ in 940 cells, or the reduced expression mediated by shRNA lentiviral constructs in PB keratinocytes. We observed that, in 940 cells (Fig. 8A), the expression of hu $\Delta \mathrm{Np} 63 \alpha$ produced a significant decrease in Myc, Oct4 and Nanog genes. In agreement, the reduced expression of $\mathrm{p} 63$ was correlated with increased expression of all these genes in PB cells (Fig. 8B). These data revealed that, besides opposing to EMT process, p63 expression may also reduce the stem cell-like properties of $\mathrm{p} 53$-deficient mouse keratinocytes, thus probably contributing to the increased malignancy. 

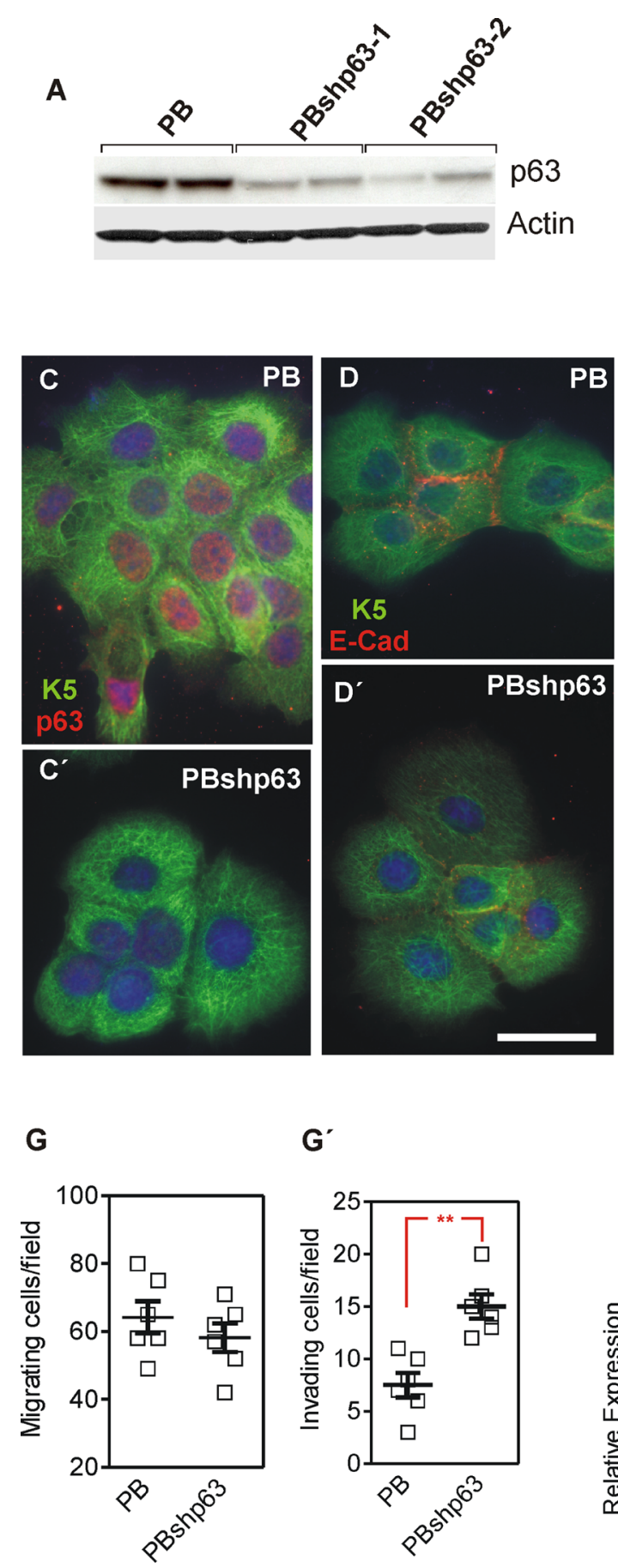

$\mathbf{G}^{\prime}$

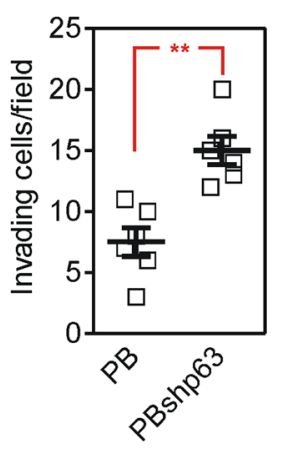

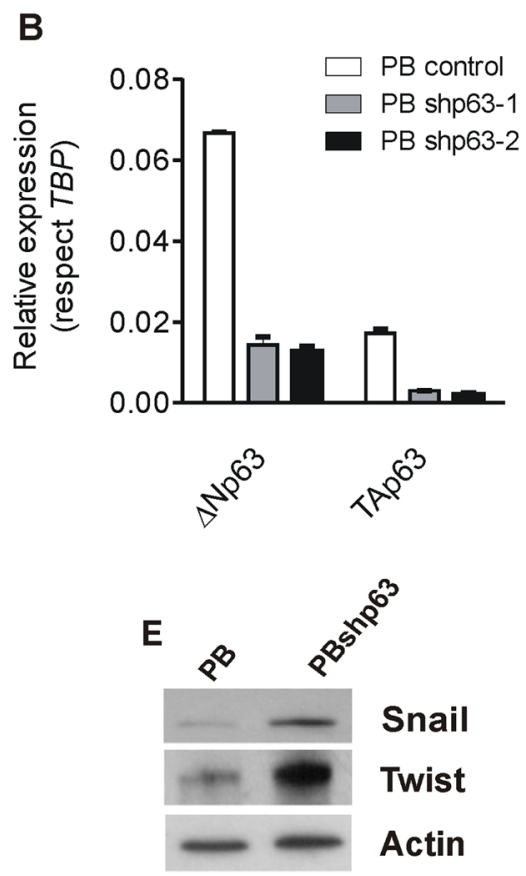
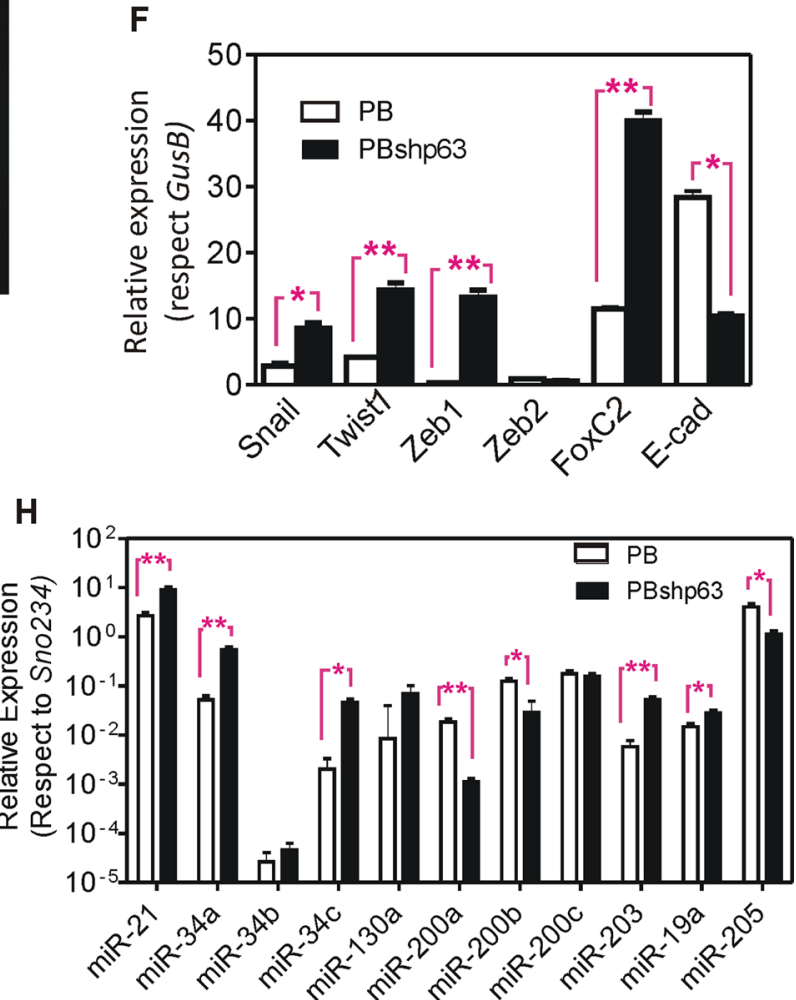

Figure 6: Knock down of p63 promotes a partial EMT process in PB transformed keratinocytes. A, B. Determination of p63 expression by immunoblot (A) or qRT-PCR (B) in parental PB cells and PB cells transduced with lentiviral constructs coding for two different shRNAs against mouse Trp63 gene. C-D' Representative immunofluorescence images of PB (C, D) and PBshp63 cells (C', D') showing in red the expression and localization of p63 (C, C') and E-Cadherin (D, D') and in green keratin K5. Bar $=20 \mu \mathrm{m}$. E. Immunoblot showing the expression of the quoted proteins in PB and PBshp63 cells. F. Determination of the expression of transcription factors involved in EMT processes, as assessed by qRT-PCR analyses, in PB and PBshp63 cells. G G'. Determination of migratory (G) and invasive (G') properties of PB and PBshp63 cells. H. Determination of the expression of miRNAs involved in EMT processes, as assessed by qRT-PCR analyses, in $\mathrm{PB}$ and PBshp63 cells. Data in $\mathrm{F}$ and $\mathrm{H}$ came from at least quadruplicated experiments. $*$ denotes $p$ value $<0.05, * *$ denotes $p$ value $<0.01$ 

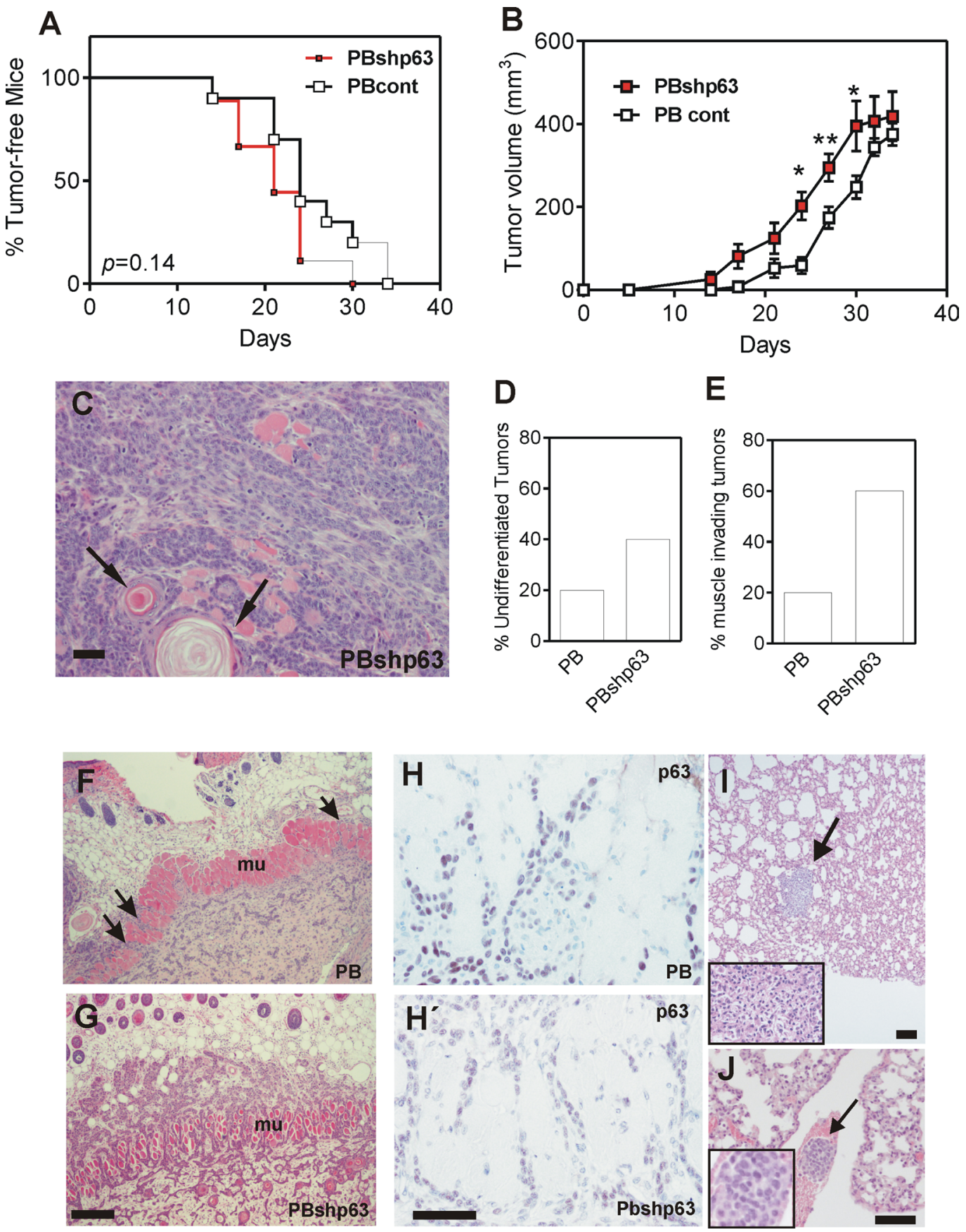

Figure 7: Knock down of p63 promotes tumor dedifferentiation and invasiveness. A. Tumor incidence upon subcutaneous injection of PB (black line) or PBshp63 cells (red line) determined by Kaplan Meyer curves. $p$ value was determined by log rank test. B. Tumor growth of subcutaneously injected PB (open squares) or PBshp63 (red squares) cells. $p$ Value was determined by 2Way ANOVA followed by Bonferroni post test. *denotes $p$ value $<0.05, * *$ denotes $p$ value $<0.01$. C. Representative image of H\&E stained subcutaneous tumor produced by the injection of PBshp63 cells showing the presence of undifferentiated and differentiated areas (denoted by arrows). Bar $=250 \mu \mathrm{m}$. D, E. Summary of differentiation status (D) and subcutaneous muscle invasion (E) of the subcutaneous tumors $(n=5$ for each group) produced by the injection of PBshp63 cells. F, G. Representative images of H\&E stained subcutaneous tumor produced by the injection of PB (F) or PBshp63 (G) cells showing the subcutaneous muscle layer invasion (denoted by arrows). Bar $=150 \mu \mathrm{m}$. H, H'. Representative immunohistochemistry images showing the expression of p63 in the muscle invasive cells of the subcutaneous tumors produced by the injection of PB $(\mathrm{H})$ or PBshp63 (H') cells. Bar $=150 \mu \mathrm{m}$. I. Metastatic nodule (denoted by arrow) observed upon tumor induction by subcutaneous injection of PBshp63 cells. Inset shows a higher magnification of the metastatic nodule. Bar $=250 \mu \mathrm{m}$. J. Representative image of $H \& E$ stained lung section showing the presence of malignant epithelial cell aggregate (denoted by arrow) in a lung blood vessel. Inset shows a higher magnification of the epithelial cell aggregate. Bar $=150 \mu \mathrm{m}$. 

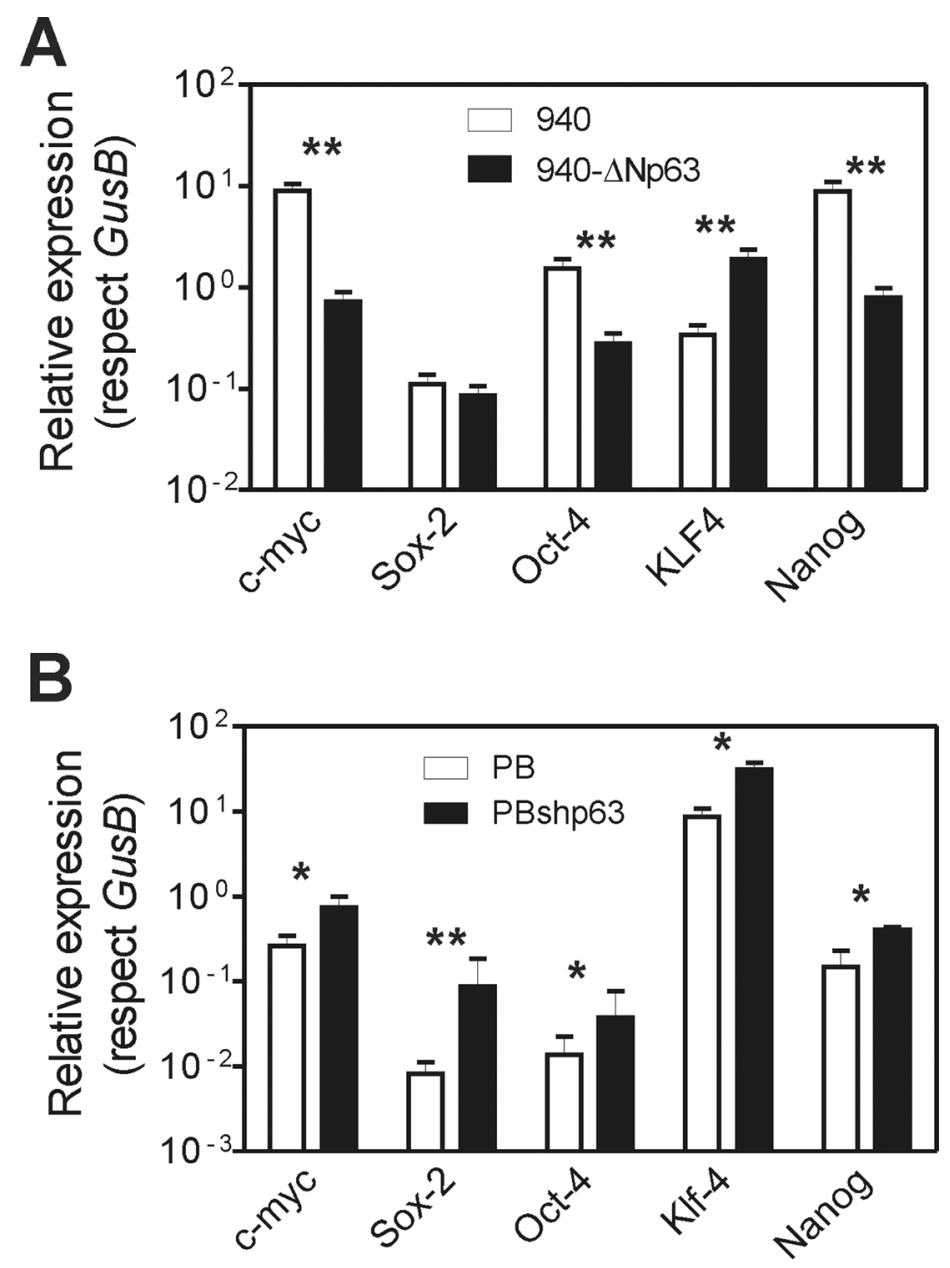

Figure 8: Altered p63 expression promotes altered expression of stemness factors. A, B. Summary of qRT-PCR determination of the levels of the quoted genes in 940 cells traduced with GFP or $\triangle \mathrm{Np} 63 \alpha$ (A), and in PB or PBshp63 cells (B) Data came from at least three independent experiments. *denotes $p$ value $<0.05, * *$ denotes $p$ value $<0.01$ by Mann Whitney $t$ Test.

\section{DISCUSSION}

The frequent amplification and overexpression of $\Delta$ Np63 in multiple epithelial cancers, have led to a general assumption that this protein behaves as an oncogene [12]. In agreement with this, $\Delta$ Np63 may repress oncogeneinduced senescence [15]. However, it has also been reported that reduction of p63 expression levels favors EMT and metastasis [20, 21, 53], and in aggressive invasive epithelial tumors $\Delta \mathrm{Np} 63$ is down regulated, suggesting that p63 may play potential roles as metastasis suppressor [16-18]. Here we provide further evidence of this function in the context of p53-deficiency (spontaneous tumors in $\operatorname{Trp} 53^{4 E p i}$ mice and 940 cells) or Trp 53 mutation (PB cells).

The deficiency in p53 confers increased susceptibility to multiple spontaneous tumor development. However, based on mouse KO models [54], it has been assumed that complete loss of function of p53 is not prone to metastasis. In spite of this assumption, the reduced expression of other p53 family members, p63 and p73, produced higher tumor burden and metastatic potential compared to heterozygous deficient p53 mice [26], thus offering the first evidence suggesting that the reduction of p63 confers metastatic potential to transformed p53deficient cells. Our present data reinforce this finding and provide possible mechanistic explanations for this role of p63 as metastasis modulator.

Tumor metastasis is the major cause of mortality of human cancers. In epithelial tumors, metastasis is associated with the loss of epithelial characteristics and the acquisition of mesenchymal properties by a genetically controlled process named epithelial mesenchymal transition (EMT), which is also essential during embryonic development $[55,56]$. These facts have posed tremendous efforts to understand the molecular mechanism controlling EMT in order to find possible therapeutic agents that impair metastatic growth of the tumors. A number of master genes controlling EMT in tumors have been identified [56]. We have previously shown that spontaneous skin tumors 
caused by the epidermal-specific deficiency in Trp53 (or simultaneous $R b 1$ and Trp53 [32]) rapidly undergo EMT process and frequently metastatize to the lungs [37]. This process is accompanied by the induction of various EMT-inducing transcription factors and deregulated expression of various miRNAs [37]. Here we show that the transcriptional downregulation of $\Delta \mathrm{Np} 63$ is an early event during tumor development in the context of p53 deficiency. Moreover, $\Delta \mathrm{Np} 63$ expression is regained in lung metastasis outgrowths, indicating that the observed downregulation of $\Delta \mathrm{Np} 63$ is not attributable to gene loss, but rather gene silencing. In addition, the re-expression of $\Delta \mathrm{Np} 63$ observed in lung metastasis, where the opposite process to EMT, the mesenchymal-epithelial transition, takes place, also suggests that $\Delta$ Np63 may play a role in this process. In agreement, the reduced p63 expression in PB keratinocytes produces impaired lung colonization, even when epithelial cell aggregates are commonly observed in the lung blood vessels. However, the absence of p63 expression in the metastatic nodules generated by hu $\Delta \mathrm{Np} 63 \alpha$-transduced 940 cells argues against this possible strict requirement. Also, it is conceivable that the absence of real metastatic nodules in PBshp63 cells could be related to a distinct pattern of p63 isoforms expressed compared to parental or hu $\Delta \mathrm{Np} 63 \alpha$-transduced 940 cells, which may interact with different regulators [57], or the intrinsic differences in Trp53 gene status (deleted in 940 and point mutated in PB cells), which may alter the metastatic behavior $[27,58]$. In this regard, it has been demonstrated that TGF $\beta$-induced malignant cell responses are repressed by p63, although the possible specific involvement of p63 isoforms ( $\triangle \mathrm{N}$ or $\mathrm{TA}$ ) has not be determined, and point mutated Trp53, but not p53 silencing, contributes to surpass such inhibition [27]. Consequently, the possible involvement of p63 re-expression in mesenchymal-epithelial transition, and the possible differential involvement of p63 isoforms in the context of mutated or ablated p53, would be the subject of future research.

The potential roles of $\triangle \mathrm{Np} 63$ preventing EMT are reinforced by the observed downregulation of EMTmediating transcription factors, such as Snail, Twist, Zeb1, Zeb2 and FoxC2 upon expression of hu $\Delta \mathrm{Np} 63 \alpha$ in 940 cells; whereas p63 silencing in PB cells caused their increased expression (with the exception of Zeb2). Interestingly, the reduced metastatic behavior observed upon expression of hu $\Delta \mathrm{Np} 63 \alpha$ in 940 cells strongly suggests that the elucidation of the possible mechanisms leading to p63 silencing (Supplementary Fig. 1D), could become interesting strategies to prevent metastatic spreading of epithelial cancers characterized by loss of TP53.

The $\Delta$ Np63 protein is able to directly modulate transcription in a positive and negative manner, and an extremely wide number of transcripts have been found to be under p63 regulation [25, 59]. Indeed, ChIP-Seq approaches have identified the binding of p63 to over 7000 genes $[20,60,61]$ and only a subset of these sites are bound by p53 in response to DNA damage [60]. A careful analysis of these ChIP-seq data revealed that p63 does not bind to any of the above mentioned transcription factors mediating EMT [60], thus indicating that the observed deregulation is probably indirect.

Among the factors that are known to modulate the expression of these transcription factors, different miRNAs have emerged as key elements [41, 62]. In this regard, we have also reported that metastatic spreading of p53-deficent epidermal tumors is associated with specific deregulation of various miRNAs [37], and ChIPseq data identified multiple miRNAs as targets for p63 regulation $[20,60]$.

In the present study we show that the experimental deregulation of p63 levels promoted altered expression of various miRNA previously involved in EMT and tumor metastasis, including miR-21, miR-34a, miR-200a, miR200b, miR-203, miR19a and miR205. Of note, several of these miRNAs have been identified in ChIP-seq experiments and display binding sites for p53 (miR-21, miR34a), p63 (miR-200a, miR-200b) or both (miR-205) $[20,60]$. Importantly, many of these miRNAs can target various transcription factors modulating EMT and whose expression is affected by p63 levels. Nonetheless, other possible mechanisms cannot be discarded at present. For instance, the altered expression of p63 isoforms can induce a metabolic rewiring in tumor cells [21, 63], and oxidative metabolism could be a critical suppressor of metastasis [64]. Future genomics studies may provide new mechanistic insights about the genes and miRNAs regulated by p63 and the molecular mechanisms underlying the observed functions.

There is wide evidence that the EMT process leads to the acquisition of embryonic stem cell-like features in various human tumors [36, 62, 65, 66]. Moreover, the transcriptome analysis of spontaneous skin tumors of $\operatorname{Trp} 53^{\triangle E p i}$ mice also revealed a significant overlap with embryonic stem cell like gene signatures [34]. More recently it has been reported that $\Delta \mathrm{Np} 63$-deficient keratinocytes display increased sensitivity to cell reprogramming to pluripotency by Yamanaka factors [52]. Importantly, most if not all of these factors are also associated with increased malignancy in squamous cell carcinoma [49-51]. We thus investigated whether altered p63 levels could induce changes in transcription factors mediating reprogramming to pluripotency. We found that partial depletion of $\Delta \mathrm{Np} 63$ is sufficient to induce the expression of Myc, Sox2, Oct4 and Nanog. Importantly, although none of these factors are directly bound by $\mathrm{p} 63$, they display post-transcriptional regulation by various miRNAs identified as targets of p63 [52]. Further, we have recently observed that overexpression of Nanog in transgenic mouse skin contributes to EMT by directly modulating the expression of Zeb2, Twist1 and miR-21 [51].

Collectively, our data reinforce the possible role of p63 as metastasis suppressor in the context of p53 
deficiency, through the regulation of various miRNAs and transcription factors that modulate the EMT processes.

\section{MATERIALS AND METHODS}

\section{Mice and cell lines}

Mouse model lacking $R b 1$ and $\operatorname{Trp} 53$, or $\operatorname{Trp} 53$ alone, in the basal layer of the epidermis have been previously described [32]. The 940, COCA and PB keratinocytes have been previously described $[37,42,46]$. To monitor in vitro migration and invasion a previously reported protocol was followed [37]. In vivo xenografts experiments are detailed in Supplementary Information. All the animal experiments were approved by the Animal Ethical Committee (CEEA) and conducted in compliance with Centro de Investigaciones Energéticas, Medioambientales y Tecnológicas (CIEMAT) guidelines.

\section{Lentivirus construction}

The sequence encoding for the human $\Delta \mathrm{Np} 63$ gene was obtained by $\mathrm{XbaI} / \mathrm{XhoI}$ digestion of the $\Delta \mathrm{Np} 63 \alpha$ FLAG vector (Adgene \#26979) and inserted into de NheI/XhoI sites of the pL105iGFP backbone lentiviral vector (kindly provided by Dr. R. Murillas). Lentivirus production is detailed in Supplementary Information. For the generation of PBshp63, PB cells were transduced using pLKO.1 Mission Lentiviral system (Sigma, TRCN0000416977 and TRCN0000423330, sequences are provided in Supplementary Table 2) following manufacturer's recommendations. A control of pLKO.1 lentivirus containing an sh sequence that targets no known mammalian genes was used. Upon infection, clones were selected by puromycin resistance (Sigma, $20 \mu \mathrm{g} / \mathrm{ml}$ ) for 2 weeks.

\section{Quantitative RT-PCR and immunoblotting}

Total RNA was isolated from mouse tissue and culture cells and as previously described [37, 67-69]. The qRT-PCR procedures for genes and miRNAs are detailed in Supplementary Materials and Methods and Supplementary Table 1.Total RNA was isolated from mouse tissue and culture cells and as previously described [37, 67-69]. The qRT-PCR procedures for genes and miRNAs are detailed in Supplementary Information. For immunoblots, protein extracts were obtained and processed as described [37]. Detailed protocols and antibodies used are provided in the Supplementary information.

\section{Immunohistochemistry and immunofluorescence}

Samples were fixed in 4\% PBS-buffered formalin or $70 \%$ ethanol, embedded in paraffin wax and sectioned $(5 \mu \mathrm{m})$. Cells were grown in glass coverslips and were fixed in cold methanol/acetone for $10 \mathrm{~min}[70,71]$. Immunohistochemistry and Immunofluorescence were performed using previously described standard protocols $[32,37]$. Antibodies used are detailed in Supplementary Information.

\section{ACKNOWLEDGMENTS}

The study was funded by the following: MINECO grant SAF2012-34378; Comunidad Autónoma de Madrid grant S2010/BMD-2470 (Oncocycle Program); AES grants ISCIII-RETIC RD06/0020/0029 and RD12/0036/0009 to J.M. Paramio. Grants AP99782012 from MMA Foundation to M. Dueñas. AES grant ISCIIIFIS PI12/01959 to M. Santos.

\section{CONFLICTS OF INTEREST}

No potential conflicts of interest were disclosed.

The funders had no role in study design, data collection and analysis, decision to publish, or preparation of the article.

\section{REFERENCES}

1. Yang A, Kaghad M, Wang Y, Gillett E, Fleming MD, Dotsch V, Andrews NC, Caput D, McKeon F. p63, a p53 homolog at 3q27-29, encodes multiple products with transactivating, death-inducing, and dominant-negative activities. Molecular cell. 1998; 2:305-316.

2. Stiewe T. The p53 family in differentiation and tumorigenesis. Nat Rev Cancer. 2007; 7:165-168.

3. Soussi T, Beroud C. Assessing TP53 status in human tumours to evaluate clinical outcome. Nat Rev Cancer. 2001; 1:233-240.

4. Toledo F, Wahl GM. Regulating the p53 pathway: in vitro hypotheses, in vivo veritas. Nat Rev Cancer. 2006; 6:909-923.

5. Petitjean A, Mathe E, Kato S, Ishioka C, Tavtigian SV, Hainaut P, Olivier M. Impact of mutant p53 functional properties on TP53 mutation patterns and tumor phenotype: lessons from recent developments in the IARC TP53 database. Hum Mutat. 2007; 28:622-629.

6. Candi E, Dinsdale D, Rufini A, Salomoni P, Knight RA, Mueller M, Krammer PH, Melino G. TAp63 and DeltaNp63 in cancer and epidermal development. Cell Cycle. 2007; 6:274-285.

7. Levine AJ, Tomasini R, McKeon FD, Mak TW, Melino G. The p53 family: guardians of maternal reproduction. Nat Rev Mol Cell Biol. 2011; 12:259-265.

8. Suh EK, Yang A, Kettenbach A, Bamberger C, Michaelis AH, Zhu Z, Elvin JA, Bronson RT, Crum CP, McKeon F. p63 protects the female germ line during meiotic arrest. Nature. 2006; 444:624-628. 
9. Yang A, Schweitzer R, Sun D, Kaghad M, Walker N, Bronson RT, Tabin C, Sharpe A, Caput D, Crum C, McKeon F. p63 is essential for regenerative proliferation in limb, craniofacial and epithelial development. Nature. 1999; 398:714-718.

10. Mills AA, Zheng B, Wang XJ, Vogel H, Roop DR, Bradley A. p63 is a p53 homologue required for limb and epidermal morphogenesis. Nature. 1999; 398:708-713.

11. Crum CP, McKeon FD. p63 in epithelial survival, germ cell surveillance, and neoplasia. Annual review of pathology. 2010; 5:349-371.

12. Hibi K, Trink B, Patturajan M, Westra WH, Caballero OL, Hill DE, Ratovitski EA, Jen J, Sidransky D. AIS is an oncogene amplified in squamous cell carcinoma. Proceedings of the National Academy of Sciences of the United States of America. 2000; 97:5462-5467.

13. Patturajan M, Nomoto S, Sommer M, Fomenkov A, Hibi K, Zangen R, Poliak N, Califano J, Trink B, Ratovitski E, Sidransky D. DeltaNp63 induces beta-catenin nuclear accumulation and signaling. Cancer Cell. 2002; 1:369-379.

14. Huang Y, Chuang A, Hao H, Talbot C, Sen T, Trink B, Sidransky D, Ratovitski E. Phospho-DeltaNp63alpha is a key regulator of the cisplatin-induced microRNAome in cancer cells. Cell death and differentiation. 2011; 18:1220-1230.

15. Keyes WM, Pecoraro M, Aranda V, VernerssonLindahl E, Li W, Vogel H, Guo X, Garcia EL, Michurina TV, Enikolopov G, Muthuswamy SK, Mills AA. DeltaNp63alpha is an oncogene that targets chromatin remodeler Lsh to drive skin stem cell proliferation and tumorigenesis. Cell Stem Cell. 2011; 8:164-176.

16. Koga F, Kawakami S, Fujii Y, Saito K, Ohtsuka Y, Iwai A, Ando N, Takizawa T, Kageyama Y, Kihara K. Impaired p63 expression associates with poor prognosis and uroplakin III expression in invasive urothelial carcinoma of the bladder. Clin Cancer Res. 2003; 9:5501-5507.

17. Piccolo S, Enzo E, Montagner M. p63, Sharp1, and HIFs: master regulators of metastasis in triple-negative breast cancer. Cancer Res. 2013; 73:4978-4981.

18. Tucci P, Agostini M, Grespi F, Markert EK, Terrinoni A, Vousden KH, Muller PA, Dotsch V, Kehrloesser S, Sayan BS, Giaccone G, Lowe SW, Takahashi N, Vandenabeele P, Knight RA, Levine AJ, et al. Loss of p63 and its microRNA-205 target results in enhanced cell migration and metastasis in prostate cancer. Proceedings of the National Academy of Sciences of the United States of America. 2012; 109:15312-15317.

19. Tran MN, Choi W, Wszolek MF, Navai N, Lee IL, Nitti G, Wen S, Flores ER, Siefker-Radtke A, Czerniak B, Dinney C, Barton M, McConkey DJ. The p63 protein isoform DeltaNp63alpha inhibits epithelial-mesenchymal transition in human bladder cancer cells: role of MIR-205. J Biol Chem. 2013; 288:3275-3288.
20. Olsen JR, Oyan AM, Rostad K, Hellem MR, Liu J, Li L, Micklem DR, Haugen H, Lorens JB, Rotter V, Ke XS, Lin B, Kalland KH. p63 attenuates epithelial to mesenchymal potential in an experimental prostate cell model. PLoS One. 2013; 8:e62547.

21. Melino G. p63 is a suppressor of tumorigenesis and metastasis interacting with mutant p53. Cell death and differentiation. 2011; 18:1487-1499.

22. Vigano MA, Lamartine J, Testoni B, Merico D, Alotto D, Castagnoli C, Robert A, Candi E, Melino G, Gidrol X, Mantovani R. New p63 targets in keratinocytes identified by a genome-wide approach. Embo J. 2006; 25:5105-16.

23. Testoni B, Borrelli S, Tenedini E, Alotto D, Castagnoli C, Piccolo S, Tagliafico E, Ferrari S, Vigano MA, Mantovani R. Identification of new p63 targets in human keratinocytes. Cell Cycle. 2006; 5:2805-2811.

24. Su X, Chakravarti D, Cho MS, Liu L, Gi YJ, Lin YL, Leung ML, El-Naggar A, Creighton CJ, Suraokar MB, Wistuba I, Flores ER. TAp63 suppresses metastasis through coordinate regulation of Dicer and miRNAs. Nature. 2010; 467:986-990.

25. Yang A, Zhu Z, Kapranov P, McKeon F, Church GM, Gingeras TR, Struhl K. Relationships between p63 binding, DNA sequence, transcription activity, and biological function in human cells. Molecular cell. 2006; 24:593-602.

26. Flores ER, Sengupta S, Miller JB, Newman JJ, Bronson R, Crowley D, Yang A, McKeon F, Jacks T. Tumor predisposition in mice mutant for $\mathrm{p} 63$ and p73: evidence for broader tumor suppressor functions for the p53 family. Cancer Cell. 2005; 7:363-373.

27. Adorno $\mathrm{M}$, Cordenonsi $\mathrm{M}$, Montagner $\mathrm{M}$, Dupont $\mathrm{S}$, Wong C, Hann B, Solari A, Bobisse S, Rondina MB, Guzzardo V, Parenti AR, Rosato A, Bicciato S, Balmain A, Piccolo S. A Mutant-p53/Smad complex opposes p63 to empower TGFbeta-induced metastasis. Cell. 2009; 137:87-98.

28. Muller PA, Caswell PT, Doyle B, Iwanicki MP, Tan EH, Karim S, Lukashchuk N, Gillespie DA, Ludwig RL, Gosselin P, Cromer A, Brugge JS, Sansom OJ, Norman JC, Vousden KH. Mutant p53 drives invasion by promoting integrin recycling. Cell. 2009; 139:1327-1341.

29. Berns EM, van Staveren IL, Look MP, Smid M, Klijn JG, Foekens JA. Mutations in residues of TP53 that directly contact DNA predict poor outcome in human primary breast cancer. British journal of cancer. 1998; 77:1130-1136.

30. Powell BL, Bydder S, Grieu F, Gnanasampanthan G, Elsaleh H, Seshadri R, Berns EM, Iacopetta B. Prognostic value of TP53 gene mutation in adjuvant treated breast cancer patients. Breast Cancer Res Treat. 2001; 69:65-68.

31. Poeta ML, Manola J, Goldwasser MA, Forastiere A, Benoit N, Califano JA, Ridge JA, Goodwin J, Kenady D, Saunders J, Westra W, Sidransky D, Koch WM. TP53 
mutations and survival in squamous-cell carcinoma of the head and neck. N Engl J Med. 2007; 357:2552-2561.

32. Martinez-Cruz AB, Santos M, Lara MF, Segrelles C, Ruiz S, Moral M, Lorz C, Garcia-Escudero R, Paramio JM. Spontaneous squamous cell carcinoma induced by the somatic inactivation of retinoblastoma and Trp53 tumor suppressors. Cancer Res. 2008; 68:683-692.

33. Moral M, Segrelles C, Lara MF, Martinez-Cruz AB, Lorz C, Santos M, Garcia-Escudero R, Lu J, Kiguchi K, Buitrago A, Costa C, Saiz C, Rodriguez-Peralto JL, Martinez-Tello FJ, Rodriguez-Pinilla M, Sanchez-Cespedes M, et al. Akt activation synergizes with Trp53 loss in oral epithelium to produce a novel mouse model for head and neck squamous cell carcinoma. Cancer Res. 2009; 69:1099-1108.

34. Garcia-Escudero R, Martinez-Cruz AB, Santos M, Lorz C, Segrelles C, Garaulet G, Saiz-Ladera C, Costa C, BuitragoPerez A, Duenas M, Paramio JM. Gene expression profiling of mouse p53-deficient epidermal carcinoma defines molecular determinants of human cancer malignancy. Molecular cancer. 2010; 9:193.

35. Duenas M, Santos M, Aranda JF, Bielza C, Martinez-Cruz AB, Lorz C, Taron M, Ciruelos EM, Rodriguez-Peralto JL, Martin M, Larranaga P, Dahabreh J, Stathopoulos GP, Rosell R, Paramio JM, GarciaEscudero R. Mouse p53-deficient cancer models as platforms for obtaining genomic predictors of human cancer clinical outcomes. PLoS One. 2012; 7:e42494.

36. Ben-Porath I, Thomson MW, Carey VJ, Ge R, Bell GW, Regev A, Weinberg RA. An embryonic stem cell-like gene expression signature in poorly differentiated aggressive human tumors. Nature genetics. 2008; 40:499-507.

37. Bornachea O, Santos M, Martinez-Cruz AB, GarciaEscudero R, Duenas M, Costa C, Segrelles C, Lorz C, Buitrago A, Saiz-Ladera C, Agirre X, Grande T, Paradela B, Maraver A, Ariza JM, Prosper F, et al. EMT and induction of miR-21 mediate metastasis development in Trp53deficient tumours. Scientific reports. 2012; 2:434.

38. Lamouille S, Subramanyam D, Blelloch R, Derynck R. Regulation of epithelial-mesenchymal and mesenchymalepithelial transitions by microRNAs. Curr Opin Cell Biol. 2013; 25:200-207.

39. Thiery JP, Acloque H, Huang RY, Nieto MA. Epithelialmesenchymal transitions in development and disease. Cell. 2009; 139:871-890.

40. Brabletz S, Brabletz T. The ZEB/miR-200 feedback loop - a motor of cellular plasticity in development and cancer? EMBO Rep. 2012; 11:670-677.

41. Huangyang P, Shang Y. Epigenetic regulation of epithelial to mesenchymal transition. Current cancer drug targets. 2013; 13:973-985.

42. Segrelles C, Holguin A, Hernandez P, Ariza JM, Paramio JM, Lorz C. Establishment of a murine epidermal cell line suitable for in vitro and in vivo skin modelling. BMC dermatology. 2011; 11:9.
43. Gregory PA, Bracken CP, Bert AG, Goodall GJ. MicroRNAs as regulators of epithelial-mesenchymal transition. Cell Cycle. 2008; 7:3112-3118.

44. McConkey DJ, Choi W, Marquis L, Martin F, Williams MB, Shah J, Svatek R, Das A, Adam L, Kamat A, Siefker-Radtke A, Dinney C. Role of epithelial-tomesenchymal transition (EMT) in drug sensitivity and metastasis in bladder cancer. Cancer metastasis reviews. 2009; 28:335-344.

45. Candi E, Amelio I, Agostini M, Melino G. MicroRNAs and p63 in epithelial stemness. Cell death and differentiation. 2015; 22:12-21.

46. Yuspa SH, Morgan D, Lichti U, Spangler EF, Michael D, Kilkenny A, Hennings H. Cultivation and characterization of cells derived from mouse skin papillomas induced by an initiation-promotion protocol. Carcinogenesis. 1986; 7:949-958.

47. Segrelles C, Ruiz S, Perez P, Murga C, Santos M, Budunova IV, Martinez J, Larcher F, Slaga TJ, Gutkind JS, Jorcano JL, Paramio JM. Functional roles of Akt signaling in mouse skin tumorigenesis. Oncogene. 2002; 21:53-64.

48. Suva ML, Riggi N, Bernstein BE. Epigenetic reprogramming in cancer. Science. New York, NY. 2013; 339:1567-1570.

49. Boumahdi S, Driessens G, Lapouge G, Rorive S, Nassar D, Le Mercier M, Delatte B, Caauwe A, Lenglez S, Nkusi E, Brohee S, Salmon I, Dubois C, del Marmol V, Fuks F, Beck B, et al. SOX2 controls tumour initiation and cancer stem-cell functions in squamous-cell carcinoma. Nature. 2014; 511:246-250.

50. Koo BS, Lee SH, Kim JM, Huang S, Kim SH, Rho YS, Bae WJ, Kang HJ, Kim YS, Moon JH, Lim YC. Oct4 is a critical regulator of stemness in head and neck squamous carcinoma cells. Oncogene. 2015; 34:2317-2324.

51. Palla AR, Piazzolla D, Alcazar N, Canamero M, Grana O, Gomez-Lopez G, Dominguez O, Duenas M, Paramio JM, Serrano M. The pluripotency factor NANOG promotes the formation of squamous cell carcinomas. Scientific reports. 2015; 5:10205.

52. Chakravarti D, Su X, Cho MS, Bui NH, Coarfa C, Venkatanarayan A, Benham AL, Flores Gonzalez RE, Alana J, Xiao W, Leung ML, Vin H, Chan IL, Aquino A, Muller N, Wang H, et al. Induced multipotency in adult keratinocytes through down-regulation of DeltaNp63 or DGCR8. Proceedings of the National Academy of Sciences of the United States of America. 2014; 111:E572-581.

53. Barbieri CE, Tang LJ, Brown KA, Pietenpol JA. Loss of p63 leads to increased cell migration and up-regulation of genes involved in invasion and metastasis. Cancer Res. 2006; 66:7589-7597.

54. Lozano G. The oncogenic roles of p53 mutants in mouse models. Current opinion in genetics \& development. 2007; 17:66-70. 
55. Moreno-Bueno G, Portillo F, Cano A. Transcriptional regulation of cell polarity in EMT and cancer. Oncogene. 2008; 27:6958-6969.

56. Peinado H, Olmeda D, Cano A. Snail, Zeb and bHLH factors in tumour progression: an alliance against the epithelial phenotype? Nat Rev Cancer. 2007; 7:415-428.

57. Candi E, Agostini M, Melino G, Bernassola F. How the TP53 family proteins TP63 and TP73 contribute to tumorigenesis: regulators and effectors. Hum Mutat. 2014; 35:702-714.

58. Tan EH, Morton JP, Timpson P, Tucci P, Melino G, Flores ER, Sansom OJ, Vousden KH, Muller PA. Functions of TAp63 and p53 in restraining the development of metastatic cancer. Oncogene. 2014; 33:3325-3333.

59. Wu G, Nomoto S, Hoque MO, Dracheva T, Osada M, Lee CC, Dong SM, Guo Z, Benoit N, Cohen Y, Rechthand P, Califano J, Moon CS, Ratovitski E, Jen J, Sidransky D, et al. DeltaNp63alpha and TAp63alpha regulate transcription of genes with distinct biological functions in cancer and development. Cancer Res. 2003; 63:2351-2357.

60. McDade SS, Henry AE, Pivato GP, Kozarewa I, Mitsopoulos C, Fenwick K, Assiotis I, Hakas J, Zvelebil M, Orr N, Lord CJ, Patel D, Ashworth A, McCance DJ. Genome-wide analysis of p63 binding sites identifies AP-2 factors as co-regulators of epidermal differentiation. Nucleic acids research. 2012; 40:7190-7206.

61. Kouwenhoven EN, van Heeringen SJ, Tena JJ, Oti M, Dutilh BE, Alonso ME, de la Calle-Mustienes E, Smeenk L, Rinne T, Parsaulian L, Bolat E, Jurgelenaite R, Huynen MA, Hoischen A, Veltman JA, Brunner HG, et al. Genome-wide profiling of p63 DNA-binding sites identifies an element that regulates gene expression during limb development in the 7q21 SHFM1 locus. PLoS Genet. 2010; 6: e1001065.

62. Wu CY, Tsai YP, Wu MZ, Teng SC, Wu KJ. Epigenetic reprogramming and post-transcriptional regulation during the epithelial-mesenchymal transition. Trends Genet. 2012; 28:454-463.

63. D'Alessandro A, Amelio I, Berkers CR, Antonov A, Vousden KH, Melino G, Zolla L. Metabolic effect of
TAp63alpha: enhanced glycolysis and pentose phosphate pathway, resulting in increased antioxidant defense. Oncotarget. 2014; 5:7722-7733.

64. Lu J, Tan M, Cai Q. The Warburg effect in tumor progression: mitochondrial oxidative metabolism as an antimetastasis mechanism. Cancer letters. 2015; 356:156-164.

65. Tam WL, Weinberg RA. The epigenetics of epithelial-mesenchymal plasticity in cancer. Nat Med. 2013; 19:1438-1449.

66. Chang CJ, Chao CH, Xia W, Yang JY, Xiong Y, Li CW, Yu WH, Rehman SK, Hsu JL, Lee HH, Liu M, Chen CT, Yu D, Hung MC. p53 regulates epithelial-mesenchymal transition and stem cell properties through modulating miRNAs. Nat Cell Biol. 2011; 13:317-323.

67. Santos M, Martinez-Fernandez M, Duenas M, GarciaEscudero R, Alfaya B, Villacampa F, Saiz-Ladera C, Costa C, Oteo M, Duarte J, Martinez V, GomezRodriguez MJ, Martin ML, Fernandez M, Viatour P, Morcillo MA, et al. In vivo disruption of an Rb-E2F-Ezh2 signaling loop causes bladder cancer. Cancer Res. 2014; 74:6565-6577.

68. Saiz-Ladera C, Lara MF, Garin M, Ruiz S, Santos M, Lorz C, Garcia-Escudero R, Martinez-Fernandez M, Bravo A, Fernandez-Capetillo O, Segrelles C, Paramio JM. p21 suppresses inflammation and tumorigenesis on pRB-deficient stratified epithelia. Oncogene. 2014; 33:4599-4612.

69. Costa C, Santos M, Martinez-Fernandez M, Duenas M, Lorz C, Garcia-Escudero R, Paramio JM. E2F1 loss induces spontaneous tumour development in Rb-deficient epidermis. Oncogene. 2013; 32:2937-2951.

70. Paramio JM, Casanova ML, Segrelles C, Mittnacht S, Lane EB, Jorcano JL. Modulation of cell proliferation by cytokeratins K10 and K16. Mol Cell Biol. 1999; 19:3086-3094.

71. Paramio JM, Jorcano JL. Assembly dynamics of epidermal keratins $\mathrm{K} 1$ and K10 in transfected cells. Exp Cell Res. 1994; 215:319-331. 